\title{
PENGEMBANGAN METODE ACTIVITY BASED TIME STUDY UNTUK SISTEM PRODUKSI ENGINEERING TO ORDER (ETO) DENGAN TIPE ALIRAN JOB SHOP
}

\author{
Ahmad Fatih Fudhla ${ }^{1, *)}$, Anda Iviana Juniani ${ }^{2)}$, Liris Windyaningrum ${ }^{3)}$ \\ 1) Jurusan Teknik Industri STT YPM, Raya Ngelom, Taman, Sepanjang, Sidoarjo \\ e-mail: fudhla04@yahoo.co.id \\ 2) Politeknik Perkapalan Negeri Surabaya (PPNS), ITS Surabaya \\ e-mail: andahome@gmail.com \\ 3) Program Studi Teknik Industri, Universitas Katolik Widya Mandala Madiun \\ e-mail: liriswindya@yahoo.com
}

\begin{abstract}
ABSTRAK
Waktu Standard setiap aktivitas operasi merupakan hal dasar yang sangat penting dalam operasi suatu perusahaan, keberadaannya dibutuhkan dalam melakukan perencanaan operasi, control hingga evaluasi terutama bagi perusahaan yang berbasis Engineering to Order yang menggunakan waktu standard untuk menentukan nilai suatu project dalam proses tender. perusahaan-perusahaan besar yang memiliki variasi jenis proses yang sangat tinggi mengalami kesulitan dalam melakukan proses pengukuran waktu standar. Metode-metode yang sudah ada, seperti stopwatch time study dan work sampling dan lain-lain kurang bisa diaplikasikan secara cepat dikarenakan variasi operasi yang sangat tinggi. Karena tipe produksinya adalah job shop dan setiap project memiliki disain dan spesifikasi yang berbeda, maka dalam penelitian ini dibuat suatu metode dan standardisasi/formula waktu baku dan standard manhours yang memiliki fleksibilitas tinggi untuk mengakomodir setiap jenis project. Dikembangkanlah metode yang men-develop metode pengukuran waktu standar untuk perusahaan Engineering to Order (EtO) dengan tipe aliran proses job shop dengan variasi dan jumlah proses yang tinggi. Hasil yang didapat dari pengukuran dan perancangan ini adalah berupa formulasi waktu baku dan formulasi standard manhours serta suatu metode baru dalam pengukuran waktu standard yang disebut Activity Based Time Study.
\end{abstract}

Kata Kunci : Activity Based Time Study, waktu baku, manhours, ETO, Job Shop

\section{PENDAHULUAN}

Job shop merupakan salah satu dari tiga tipe desain proses produksi (flow shop, job shop dan fixed site manufacturing). Pada desain proses produksi ini, penempatan peralatan/fasilitas produksi diletakkan berdasarkan fungsinya. Perbedaan tipe operasi muncul di setiap work center atau departemen karena job mengalir antar work center, atau antar departemen (Fogarty at al., 1991). Dalam setiap operasi yang ada dalam tipe job shop, produk yang diproses memiliki variasi part yang tinggi, artinya part yang berbeda bisa diproduksi pada waktu yang singkat tanpa perubahan dengan skala luas dalam operasi produksi dan dalam pergantian tool (Kalpakjian, 1995).

Menurut Fogarty at al. (1991), terdapat 9 karakteristik yang menonjol yang dimiliki oleh job shop process:

1. Produksinya multipurpose, dan peralatan material handling bisa disesuaikan dan dimodifikasi untuk mengakomodir banyaknya perbedaan pada setiap produk.

2. Banyak produk yang berbeda berjalan dalam lot atau batch di dalam plant. 
3. Pemrosesan order membutuhkan perencanaan dan kontrol yang detil sesuai dengan variasi dari pola aliran dan pemisahan antar work center.

4. Kontrol membutuhkan detil kerja dan shop information, termasuk urutan proses, order priority, waktu yang dibutuhkan dalam tiap-tiap job, status job yang sedang dalam proses, kapasitas work center, dan kapasitas yang dibutuhkan dari work center kritis oleh periode waktu.

5. Perbedaan beban kerja setiap work center cukup besar. Masing-masing memiliki persen kapasitas utilisasi yang berbeda.

6. Ketersediaan resource, termasuk material, personal, perkakas (tools), harus dikoordinasikan dengan order planning.

7. Jumlah Work in Process (WIP) material cenderung tinggi relatif terhadap aliran proses, antrian dan lama waktu proses.

8. Menggunakan teknik penjadwalan produksi tradisional.

9. Tenaga kerja langsung (direct labor) biasanya terlatih dan memiliki skill yang tinggi.

Engineering to Order (EtO) yang juga disebut sebagai project based manufacturing, merupakan suatu pendekatan proses produksi, dimana produk didisain dan dibuat sesuai spesifikasi yang diminta oleh customer (Chase at al., 2001)

Berdasarkan sembilan karakteristik di atas dengan tipe EtO, sifat dari task/kerja yang ada pada Job Shop adalah: waktu proses singkat/pendek, non repetitive (task bervariasi tinggi), produk juga bervariasi.

Menurut Mundel (1981), waktu standar merupakan sebuah fungsi jumlah kebutuhan waktu untuk menyelesaikan satu unit kerja/task yang;

1. menggunakan metode dan peralatan yang diberikan

2. di bawah kondisi kerja tertentu

3. oleh seorang pekerja yang memiliki skill yang ditentukan pada job dan ketangkasan khusus untuk job tersebut, dan/atau

4. bekerja dengan menggunakan kekuatan maksimum tanpa efek yang berbahaya bagi kesehatan.

Waktu standar sangat penting kegunaannya dalam dunia industri. Menjadi elemen dasar dalam perencanaan dan pengoperasian sistem produksi, dari penyusunan jadwal produksi, mengorganisasi para pekerja untuk memproses produk, hingga melakukan kalkulasi dan estimasi waktu pengiriman (Niebel, 1999).

Terdapat banyak cara atau teknik pengukuran waktu standar. Oleh Dosset (1995) dikelompokkan menjadi lima teknik; motion analysis, time study, activity sampling, historical data, dan estimasi. Dalam study yang dilakukan olehnya (Work-measured labor standards The state of the art, 1995), didapatkan karakteristik masing-masing teknik dilihat dari sifat task/kerja yang dijadikan obyek, yakni:

- Motion analysis

- Time study

- Activity sampling

- Historical data

- Estimasi

Pada kajian literatur di atas tentang job shop EtO didapatkan bahwa sifat task/kerja pada tipe disain proses produksi ini adalah waktu prosesnya singkat/pendek, non-repetitif, task bervariasi. Jika dibandingkan dengan hasil kajian oleh Dosset (1995), maka terdapat gap di sini, dalam artian bahwa teknik pengukuran waktu standar yang sudah ada tidak bisa langsung diaplikasikan untuk perusahaan yang bertipe job shop EtO dengan variasi produk dan proses yang tinggi. Maka perlulah dibuat suatu teknik pengukuran baru yang mengakomodir karakteristik ini. 


\section{PEMBAHASAN METODE YANG DIKEMBANGKAN}

Langkah-langkah metode yang telah berhasil disusun adalah sebagai berikut

1. Deskripsi operasi

berisikan tentang identifikasi dan pendeskripsian tentang operasi yang akan diukur standar waktunya. Operasi di-breakdown hingga level sequence elemen kerja. Misalkan, operasi yang diamati adalah operasi penyambungan pipe yang memiliki sequence elemen kerja: fitting and tuck weld yang dilanjutkan butt joint welding pipe. Pada tahapan ini, juga diidentifikasi spesifikasi teknis dari masing-masing elemen kerja.

2. Identifikasi trigger activity dan driver parameter

Trigger activity merupakan sesuatu hal dalam elemen kerja yang sangat mempengaruhi lama tidaknya elemen kerja diselesaikan, semakin besar trigger activity semakin lama elemen kerja diselesaikan, begitu juga sebaliknya. Sedangkan driver parameter merupakan suatu parameter standar yang ada dalam elemen (baik spesifikasi teknik pada material, alat kerja atau pada operator) yang secara langsung mempengaruhi besar kecilnya trigger activity.

Misalkan untuk elemen kerja butt joint welding pipe, penyambungan dua pipa kembar secara horizontal, pada prinsipnya adalah mengisikan filler welding pada suatu volume melingkar berbentuk cincin pada bagian sambungan sebagaimana diperlihatkan pada Gambar 1.

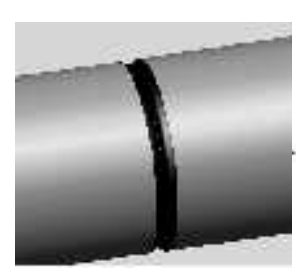

(a)

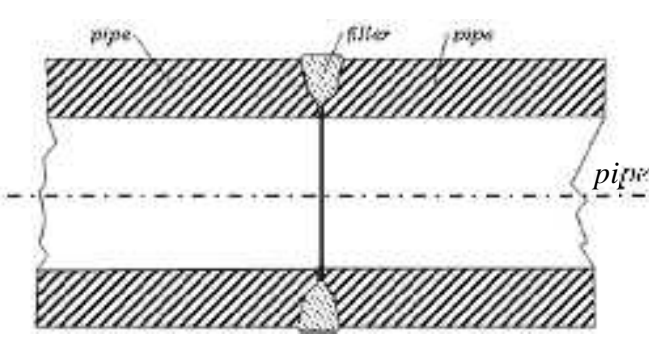

(b)

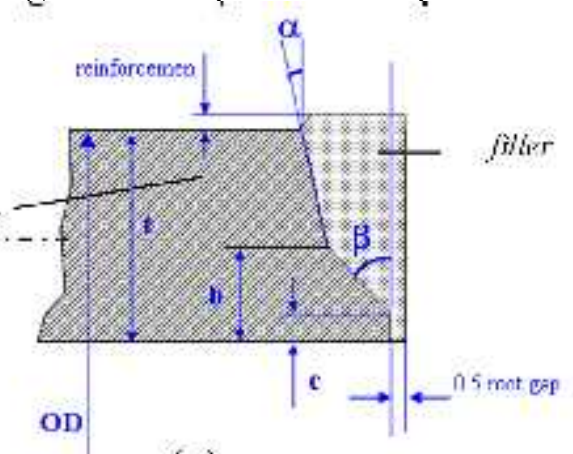

(c)

Gambar 1. Ilustrasi sambungan dua pipa horizontal

Pengisian volume inilah yang disebut trigger activity.

Volume cincin filler dihitung dengan rumusan sebagai berikut;

Jika diketahui variabel-variabel sebagaimana gambar 1(c), maka dengan menggunakan aplikasi integral untuk volume benda putar didapatkan volume filler sebagai berikut:

Volume 2:

$$
\begin{aligned}
& V_{2}=2 \times \pi \int_{0}^{a 1}\left[-x+\left(\frac{O D}{2}+e\right)\right]^{2} d x \\
& V_{2}{ }^{\prime}=2 \times \pi \int_{0}^{a 1}\left(\frac{O D}{2}+e\right)^{2} d x \text { dimana } a 1=(t-b) \tan \alpha \\
& V_{2}=V_{2}{ }^{\prime}-V_{2}^{\prime \prime}
\end{aligned}
$$

Volume 3:

$$
V_{3}=2 \times \pi \int_{0}^{a 3}\left[\left(\tan \left(\frac{\pi}{2}-\alpha\right)\right) x+\left(\frac{O D}{2}-t+b\right)\right]^{2} d x
$$

Dimana $a 3=a 1$

Volume 4:

$$
V_{3}=2 \times \pi \int_{0}^{a 4}\left[\left(\tan \left(\frac{\pi}{2}-\beta\right)\right) x+\left(\frac{O D}{2}-t+c\right)\right]^{2} d x
$$


Dimana $a 4=(b-c) \tan \beta$

Volume 5:

$$
V_{5}=\pi \int_{0}^{a 5}\left(\frac{O D}{2}-t\right)^{2} d x
$$

Volume 1:

$$
\text { Dimana } a 5=\frac{d}{2}
$$

$$
V_{1}=2 \times \pi \int_{0}^{a}\left(\frac{O D}{2}+e\right)^{2} d x
$$

Dimana $a=(t-c) \times \tan (\beta)+\frac{d}{2}$ atau $a=a 1+a 4+a 5$ dan $e=$ reinforcement; $d=$ rootgap; $\mathrm{OD}=$ Outer diameter

Sehingga volume filler total adalah:

$$
V_{\text {tot }}=V_{1}-\left(V_{2}+V_{3}+V_{4}+V_{5}\right)
$$

Dengan menggunakan formulasi di atas, untuk Outer diameter 5 inchi didapatkan volume filler sebesar 1.23 inchi $^{3}$.

Pipa merupakan material standar yang memiliki ukuran-ukuran standar di wilayah neagara manapun. Spesifikasinya adalah diameter dan jenis material. Ketebalannya pun standar dan mengikuti dua hal tersebut. Dimanapun berada pipa berdiameter 10 inchi memiliki ketebalan yang sama. Dari 2 spesifikasi standar pipa tadi, yang sangat berpengaruh pada trigger activity adalah diameter, karena volume cincin filler sangat dipengaruhi oleh diameter dari pipa yang disambung (volume filler tergantung pada keliling penampang pipa, dan keliling penampang pipa tergantung pada Diameter penampang pipa). Sehingga yang menjadi driver parameter adalah diameter pipa.

3. Pengukuran waktu kerja elemen

Pengukuran waktu elemen mengadopsi metode sopwatch time study. Pada tahap ini juga dilakukan uji homogenitas dan kecukupan data dari jumlah data waktu yang diambil.

Misalkan, setelah diambil data, uji homogenitas dan kecukupan data didapatkan waktu elemen butt jointwelding pipe:

Tabel 1. Data waktu elemen kerja butt joint welding pipe

\begin{tabular}{|c|c|}
\hline No & waktu elemen (detik) \\
\hline 1 & 937 \\
\hline 2 & 839 \\
\hline 3 & 923 \\
\hline 4 & 958 \\
\hline 5 & 969 \\
\hline 6 & 925 \\
\hline 7 & 816 \\
\hline 8 & 894 \\
\hline 9 & 797 \\
\hline 10 & 934 \\
\hline 11 & 837 \\
\hline 12 & 953 \\
\hline 13 & 899 \\
\hline mean & 898.54 \\
\hline
\end{tabular}


4. Penentuan allowance dan performance rating

Penentuan allowance dan performance rating menggunakan Westinghouse table. Misalkan untuk elemen kerja ini didapatkan allowance dan performance sebesar:

Tabel 2. performance rate dan allowance

\begin{tabular}{|lll|lll|}
\hline Skill & average & $0 \%$ & tenaga & Ringan & $5 \%$ \\
effort & average & $0 \%$ & gerakan kerja & Bebas & $2 \%$ \\
total & & $0 \%$ & kelelahan mata & Focus & $15 \%$ \\
& & & temperatur kerja & Sedang & $10 \%$ \\
& & keadaan lingkungan & kurang & $6 \%$ \\
& & kebutuhan pribadi & pria & $2 \%$ \\
\hline
\end{tabular}

5. Penyusunan formula

Dasar perhitungan waktu standar menggunakan rumusan:

waktu standar $=$ waktu amatan $\times(1+\%$ allowance $) \times(1+\%$ performance $)$ Waktu standard ini dikonversikan kedalam formula dengan membaginya dengan trigger activity yang kemudian disusun formulasi yang didalamnya terdapat driver parameter.

Misalkan elemen kerja butt joint welding pipe 5 inchi OD, waktu amatan didapatkan dari table 1 yakni sebesar 898.54 detik. Dari table 2, allowance dan performance masing-masing $40 \%$ dan $0 \%$, sehingga didapatkan waktu standar;

$$
\begin{aligned}
\text { Waktu standar } & =898.54 \times(1+40 \%) \times(1+0 \%) \\
& =1257.95 \mathrm{detik}
\end{aligned}
$$

Dengan volume filler 1.23 inchi $^{3}$, maka waktu standar amatan adalah 1257.95 detik per $1.23 \mathrm{inchi}^{3}$

Standardisasi formula;

Volume filler sangat tergantung pada keliling penampang, dan keliling penampang sangat tergantung pada atau bias didekati dengan Outer diameter (driver parameter), sehingga bias dibuat suatu persamaan sederhana;

$$
\begin{aligned}
& V_{\text {baru }}=\frac{O D_{\text {baru }}}{O D_{\text {amatar }}} V_{\text {amatan }} \\
& V_{\text {baru }}=\frac{O D_{\text {baru }}}{5} 1.23
\end{aligned}
$$

Sehingga didapatkan formulasi standard untuk butt joint welding pipe(bjwp):

bjwp standard time formula $=\frac{1257.95 \text { detik }^{2}}{1.23 \text { inch }^{3}} \times V_{\text {baru }}$

bjwp standard time formula $=\frac{1257.95 \text { detik }}{1.23 \text { inch }^{3}} \times \frac{O D_{\text {baru }}}{5 \text { inchi }} \times 1.23$ inch $^{3}$

bjwp standard time formula $=\frac{1257.95 \text { detik }}{5 \text { inchi }} \times O D_{\text {baru }}$

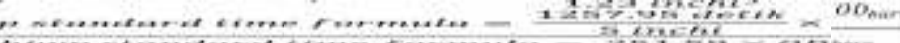

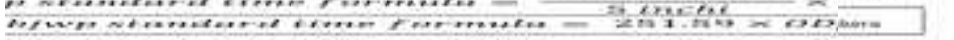

Perlu diperhatikan bahwa, formula (10) diatas dibentuk oleh operator dengan performansi average $(0 \%)$ sehingga dengan ditambahkan aspek performansi menjadi 


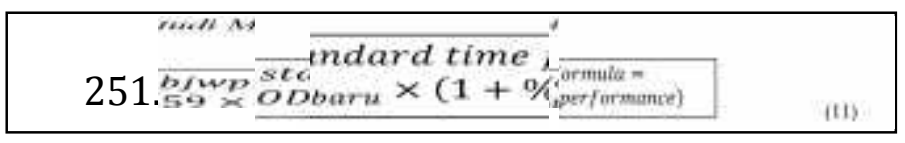

6. Validasi formula

Validasi formula dilakukan dengan membandingkan formulasi yang sudah didapatkan dengan amatan perhitungan langsung dengan stopwatch untuk diameter yang berbeda. Dengan catatan, lokasi dan kondisi stasiun kerja sama.

Tabel 3. Rekapitulasi perbandingan hasil waktu dari formula dan amatan

\begin{tabular}{|c|c|r|r|}
\hline OD & $\begin{array}{c}\text { performansi } \\
\text { operator }\end{array}$ & $\begin{array}{c}\text { waktu hasil } \\
\text { formula }\end{array}$ & $\begin{array}{c}\text { waktu hasil } \\
\text { amatan }\end{array}$ \\
\hline 7 & $0 \%$ & 1761.13 & 1757.37 \\
\hline 7 & $15 \%$ & 2025.29 & 2001.89 \\
\hline 9 & $0 \%$ & 2264.31 & 2265.77 \\
\hline 10 & $0 \%$ & 2515.9 & 2508.92 \\
\hline 3 & $0 \%$ & 754.77 & 759.12 \\
\hline
\end{tabular}

Dengan menggunakan uji statistik 2 sample $\mathrm{t}$ test dengan hipesa;

$\mathrm{H}_{0}: \mu_{1}-\mu_{2}=0$

$\mathrm{H}_{1}: \mu_{1-} \mu_{2} \neq 0$

didapatkan hasil;

Two-Sample T-Test and $\mathrm{Cl}$ : waktu hasil formula, waktu hasil amatan

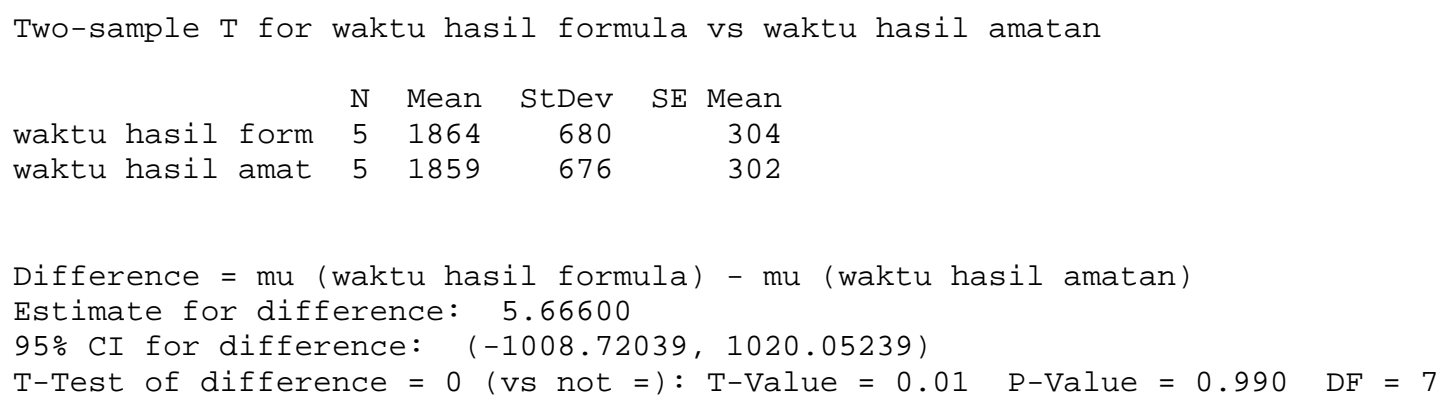

Karena p-value $=0.99$ lebih besar dari alfa 0.05 , maka terima $\mathrm{H}_{0}$, yakni antara hasil formula dan hasil amatan, secara statistik tidak terdapat bukti adanya perbedaan dan formulasi valid

Sehingga untuk elemen kerja butt joint welding pipe, pada stasiun kerja yang sama, berapapun diameter pipa yang disambungkan, maka untuk menentukan waktu standar bisa dengan menggunakan formula;

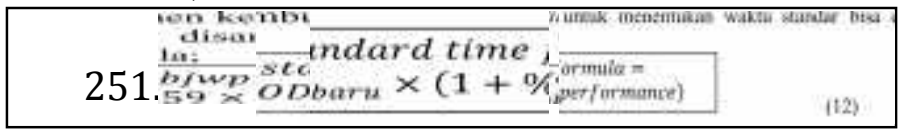

Berikut ini adalah contoh rekapitulasi formula elemen kerja lainnya yang telah dirumuskan; 
Tabel 4. Contoh formulasi waktu standard yang dihasilkan dengan metode Activity Based Time Study

\begin{tabular}{|c|c|c|c|c|}
\hline \multirow{2}{*}{ No } & \multicolumn{3}{|c|}{ Sequences } & \multirow{2}{*}{$\begin{array}{l}\text { Formulasi standard time } \\
\text { (second per unit part) }\end{array}$} \\
\hline & Suboperasi & Worke & ements & \\
\hline \multirow[t]{6}{*}{1} & \multirow{6}{*}{$\begin{array}{l}\text { End plug } \\
\text { welding } \\
(\mathrm{SO}-\mathrm{I})\end{array}$} & \multicolumn{2}{|c|}{$\begin{array}{l}\text { Grinding } \\
\text { preparation }\end{array}$} & $4.75 \times \pi \times I D_{\text {header }} \times(1+\%$ performance $)$ \\
\hline & & \multicolumn{2}{|c|}{$\begin{array}{l}\text { Fitting \& tack } \\
\text { weld }\end{array}$} & $26.98 \times \pi \times I D_{\text {header }} \times(1+\%$ performance $)$ \\
\hline & & \multicolumn{2}{|c|}{ Root-pass GTAW } & $95.69 I D_{\text {header }} \times(1+\%$ performance $)$ \\
\hline & & \multirow{2}{*}{ Preheat } & Elemen & $((16+(5 \times n)) \times 60+1) \times(1+\%$ performance $)$ \\
\hline & & & flame & $2.24 \times \pi \times O D_{\text {header }} \times(1+\%$ performane $)$ \\
\hline & & \multicolumn{2}{|c|}{ FCAW welding } & $201 \times\left(V_{\text {filler_endplug }}-\left(1.79 \times I D_{\text {header }}\right)\right) \times(1+\%$ performarce $)$ \\
\hline \multirow[t]{4}{*}{2} & \multirow{4}{*}{$\begin{array}{l}\text { Fit-up } \\
\text { nozzle \& } \\
\text { lug to } \\
\text { header } \\
\text { (SO-II) }\end{array}$} & \multicolumn{2}{|c|}{$\begin{array}{l}\text { Nozzle } \\
\text { preparation }\end{array}$} & $7.96 \times \pi \times O D_{\text {nozzle }} \times(1+\%$ performance $)$ \\
\hline & & \multicolumn{2}{|c|}{ Lugs preparation } & $13.11 \times(2 p+2 l) \times(1+\%$ performance $)$ \\
\hline & & \multicolumn{2}{|c|}{$\begin{array}{l}\text { Fit up nozzle to } \\
\text { header }\end{array}$} & $19.06 \times \pi \times I D_{\text {nozzle }} \times(1+\%$ performance $)$ \\
\hline & & \multicolumn{2}{|c|}{$\begin{array}{l}\text { Fit Up Lugs to } \\
\text { Header }\end{array}$} & $120.07 \times(2 p+2 l) \times(1+\%$ performan ce $)$ \\
\hline 3 & $\begin{array}{l}\text { Root-pass } \\
\text { nozzle to } \\
\text { header } \\
\text { (SO-III) }\end{array}$ & & & $135.4 I D_{\text {nozzle }} \times(1+\%$ performan ce $)$ \\
\hline \multirow[t]{4}{*}{4} & \multirow{4}{*}{$\begin{array}{l}\text { Flux-cored } \\
\text { welding } \\
(\mathrm{SO}-\mathrm{IV})\end{array}$} & \multirow{2}{*}{ preheat } & Elemen & $((16+(5 \times n)) \times 60+1) \times(1+\%$ performance $)$ \\
\hline & & & flame & $2.24 \times \pi \times O D_{\text {header }} \times(1+\%$ performance $)$ \\
\hline & & \multicolumn{2}{|c|}{$\begin{array}{l}\text { Flux-cored nozzle } \\
\text { to header }\end{array}$} & $1055 \times\left(V_{\text {fillernozzetoheader }}-\left(0.29 \times I D_{\text {nozzle }}\right)\right) \times(1+\%$ performance $)$ \\
\hline & & \multicolumn{2}{|c|}{$\begin{array}{l}\text { Flux-cored lug to } \\
\text { header }\end{array}$} & $366.94 \times(2 p+2 l) \times(1+\%$ performarce $)$ \\
\hline
\end{tabular}

\section{KESIMPULAN DAN SARAN}

Dengan menggunakan formulasi yang dihasilkan metode Activity based Time Study (ABTS), perusahaan yang memiliki tipe EtO dengan aliran job Shop, tidak perlu kesulitan lagi dalam melakukan pengukuran waktu standar di setiap operasinya, tidak perlu lagi kesulitan dalam melakukan penaksiran harga produk dalam manhours. Dengan meng-input-kan driver parameter ke dalam formula akan didapatkan proyeksi waktu standar yang dengan mudah bisa dikonversikan ke dalam menhours dengan dibagi angka 3600 untuk setiap operator.

Pangembangan metode ABTS ini, masih berada di tahap awal pengembangan. Masih banyak kelemahan yang perlu untuk diperbaiki. Misalnya dalam penentuan allowance dan performansi, perlu dilakukan penelitian lebih lanjut untuk penentuan besar prosentase di masing-masing kategori. 


\section{DAFTAR PUSTAKA}

Chase, Aquilano dan Jacobs, F. Robert, 2001, Operation Management for Competitive Advantage, International Edition, New York: McGraw Hill.

Dossett, Royal J., 1995, Work-Measured Labor Standards The State of The Art, Industrial Engineering, Issue 4, ProQuest Science Journals pg. 21

Fogarty, Blackstone dan Hoffmann, Thomas R., 1991 Production \& Inventory Management, 2nd edition, Ohio: South-Western Publishing Co.

Iftikar Z Sutalaksana. 1987. Teknik Tata Cara Kerja. Institut Teknologi Bandung. Bandung

Kalpakjian, Serope, 1995, Manufacturing Engineering and Technology, 3rd edition, New York: Addison-Wesley Publishing.

Mundel, Marvin E., 1981, Motion and Time Study Improving Productivity, 5th edition, New Delhi: Prentice Hall of India Private Limited.

Niebel, Benjamin dan Freivalds, Andris, 1999, Method Standard and Work Design, 10th edition, New York: McGraw Hill

Sritomo Wignjosoebroto (1996), Ergonomi, Studi Gerak dan Waktu, Jakarta, PT Guna Widya. 